\title{
Effects of Voice Therapy Using Gliding and Humming in Dysphonic Patients With Glottal Gap
}

\author{
Dae-Yong Jung (D), Mi-Ran Shim (D), Yeon-Shin Hwang (D), Geun-Jeon Kim (D), and Dong-II Sun (D) \\ Department of Otorhinolaryngology-Head and Neck Surgery, Seoul St. Mary's Hospital, The Catholic University of Korea College of Medicine, \\ Seoul, Korea
}

활창과 허밍을 이용한 음성치료가 성문틈 환자의 음성 개선에 미치는 효과

정대용, 심미란, 황연신, 김근전, 선동일

가톨릭대학교 의과대학 서울성모병원 이비인후과학교실

Background and Objectives Therapies have been reported to treat the glottal gap previously. However, these voice therapies showed the limits because many techniques focused only on one among breathing, resonance and phonation. In addition patients often have difficulties visiting hospital frequently. 'Gliding and humming' is vocal training technique that readjusts total vocal patterns such as breathing, resonance and phonation. This technique can be easily applied during short term sessions. The purpose of this study is to evaluate the efficiency of voice therapy with 'gliding and humming' for patients with glottic gap during short-term treatment sessions. Materials and Method Twenty-three patients with glottal gap were selected. Of all patients, 14 patients had sulcus vocalis and 12 patients had muscle tension dysphonia (MTD). Voice therapies were performed 1.9 sessions in average. GRBAS, jitter, shimmer, noise to harmonic ratio, semitone range, closed quotient_vowel and maximum phonation time were compared before and after the therapies. In addition, changes of glottal gap and MTD severity were evaluated. Results Statistically significant improvement was observed. MTD improvement was observed only among the patients with glottal gap improvement. Also sulcus vocalis group showed the statistically significant improvement.

Conclusion 'Gliding and humming' was effective to the patients with glottic gap and sulcus vocalis. Also, among patients who have both glottic gap and MTD, the data suggests that voice therapy for glottic gap also makes improvement in MTD.

Keywords Glottal gap; Sulcus vocalis; Voice therapy; Gliding; Humming.

\section{서 론}

성문틈(glottal gap)은 기질적 또는 기능적 원인으로 발성 시 불완전한 성대 접촉이 나 타나는 것을 말한다. 이는 성대결절(vocal nodules), 성대폴립(vocal polyp)과 같은 양성 종양이나 성대구증(sulcus vocalis), 노인성 음성장애(presbyphonia)와 같이 성문폐쇄 부전을 일으키는 질환에서 나타날 수 있으며[1], 성대 점막 질환이나 신경학적 문제가 없 는 환자들에게도 나타날 수 있다. 성문틈은 최대연장발성시간(maximum phonation time,

\author{
Received March 23, 2021 \\ Revised May 19, 2021 \\ Accepted July 14, 2021
}

\section{Corresponding Author}

Dong-ll Sun, MD, PhD

Department of Otorhinolaryngology-

Head and Neck Surgery,

Seoul St. Mary's Hospital,

The Catholic University of Korea

College of Medicine,

222 Banpo-daero, Seocho-gu,

Seoul 06591, Korea

Tel +82-2-2258-6212

Fax +82-2-2258-1378

E-mail hnsdi@catholic.ac.kr

\section{ORCID iDs}

Dae-Yong Jung (iD https://orcid.org/0000-0003-0328-227X Mi-Ran Shim (D)

https://orcid.org/0000-0001-9105-7237 Yeon-Shin Hwang (D)

https://orcid.org/0000-0001-6914-0149 Geun-Jeon Kim (D) https://orcid.org/0000-0002-5032-5853 Dong-II Sun (D)

https://orcid.org/0000-0001-9950-568X

This is an Open Access article distributed under the terms of the Creative Commons Attribution Non-Commercial License (https://creativecommons.org/ licenses/by-nc/4.0) which permits unrestricted non-commercial use, distribution, and reproduction in any medium, provided the original work is properly cited. 
$\mathrm{MPT}$ ) 감소, 공명 감소, 음질 저하, 후두부 긴장 등의 문제를 일으켜 정상적인 음성 산출을 방해하며[2], 불완전한 성대접 촉으로 인해 2차성(secondary) 근긴장성 발성장애(muscle tension dysphonia, MTD)가 나타날 수 있다[1].

이러한 성문틈 환자들의 치료로 음성치료가 시행되고 질 환유형에 따라 음성치료 접근이 크게 두 가지로 나뉜다. 양성 종양으로 인한 성문틈 환자들의 음성치료는 주로 음성위생교 육과 부드러운 발성(soft phonation) 훈련으로 성대접촉을 최 소화하여 양성 종양을 제거하는 치료법을 적용하지만[3], 양 성 종양이 없는 성문틈 환자들은 성대접촉을 유도하여 성문 틈을 줄여주는 치료법을 시행한다.

특히 성대접촉을 유도하는 음성치료가 필요한 질환으로 성 대마비(vocal fold paralysis), 노인성 음성장애, 성대구증, 기 능성 음성장애(functional dysphonia) 등이 있다. 많은 선행 연구에서 성문틈을 줄여 주는 치료 접근법으로 음성기능훈 련(vocal function exercise, VFE), 반폐성도훈련(semi occluded vocal tract exercises), 리실버만 음성치료(Lee Silverman voice therapy) 등을 사용하고 있으며 그 효과를 보 고하고 있다[4].

기존의 연구들은 이러한 음성치료 기법이 성문틈 환자의 음성 개선에 효과적이라고 보고하였으나 보통 장기간의 치료 를 필요로 하였는데[5], 보험 및 비용 문제 또는 병원과의 거 리 문제로 인하여 주기적으로 쉽게 내원할 수 없는 환자들이 많았으며[6], 본 연구자의 실제 임상 경험에서 성문틈의 특성 상 고령의 환자들이 많아 복잡한 치료 단계에 어려움을 호소 하기도 하였다.

또한 성문틈 환자들은 $\mathrm{MTD}$ 를 동반하고 있는 경우가 많 고, 성대구증 또는 $\mathrm{MTD}$ 를 동반한 성문틈 환자들은 후두 이 상 소견이 없는 성문틈 환자들에 비해 치료 효과가 떨어진다 고 보고되었다[7]. 특히, 성대구증으로 인한 성문틈 환자들의 치료 효과에 대한 연구 보고는 그 수가 많지 않았으며, 적은 수의 환자를 대상으로 하는 등 다른 질환 치료 연구에 비해 제한되어 있었다[8,9].

이에 본 연구자는 후두의 양성 종양 없이 성문틈이 관찰된 환자의 음성 개선 효율성을 높일 수 있는 치료 방법을 고안 해 보고자, VFE에 포함되는 활창훈련(gliding)과 반폐성도 훈련 중 하나인 허밍(humming)을 함께 적용하여 성문틈 환 자에게 단기간 음성 개선 효과가 있는지 살펴보고자 하였다. 또 성문틈 환자들은 $\mathrm{MTD}$ 를 동반하는 경우가 많으므로 전 체 대상자 중 $\mathrm{MTD}$ 를 동반한 성문틈 환자들의 후두 소견을 분석하여 이 치료법이 MTD 개선에도 영향을 미치는지 알아 보고자 하였다. 더불어 비교적 음성치료에 대한 보고가 제한 되어 있는 성대구증 환자에게도 음성 개선의 효과가 있는지
알아보기 위해, 전체 대상자 중 성대구증으로 인한 성문틈 환 자를 대상자로 하여 본 연구자가 재구성한 방법이 음성 개선 에 효과가 있는지 알아보고자 하였다.

\section{대상 및 방법}

\section{연구 대상}

2020년 3월에서 2021년 2월까지 본원 이비인후과 내원한 환자 중, 비디오스트로보스코피(videostroboscopy)를 통한 후두 소견 검사에서 이비인후과 전문의에 의해 성문틈이 관 찰되어 음성치료가 의뢰된 환자들의 의무기록을 후향적으로 분석하였다. 이 중 성대결절, 성대폴립과 같은 성대 종양을 동 반하고 있는 환자, 신경학적 후두 질환이 있는 환자, 후두미세 수술 경험이 있는 환자, 음성치료 과거력이 있는 환자들은 대 상자에서 제외하였고, 성대 양성 종양 없이 성문틈만 있는 환 자와 성대구증으로 인한 성문틈 환자가 주된 대상자로 선정 되었다. 초기 대상자는 39명이었으나 치료 후 음성 검사가 시 행되지 않은 환자들을 제외하고 남성 13 명, 여성 10 명, 총 23명 의 환자를 선정하였으며, 환자의 평균연령은 61.6세(41-79세) 였다. 전체 대상자 중 성대구증으로 진단된 환자는 14 명이었 고, 성대 양성 종양 없이 성문틈으로 진단된 환자는 9명으로 나타났다. 또한 전체 대상자 중 MTD를 동반한 환자는 12 명 이었고, 이 중 성대구증 환자는 9 명, 성대 양성 종양 없이 성문 틈으로 진단된 환자는 3 명이었다.

본 연구는 성문틈 환자 23 명의 음성치료 전후 결과를 비교 하고, 전체 대상자 중 MTD를 동반한 환자의 MTD 개선 정 도를 분석하였으며, 나아가 전체 대상자 중 성대구증 환자만 을 따로 분류하여 음성치료 전후의 음성을 비교하였다. 아울 러 본 연구는 서울성모병원 임상시험심사위원회에서 검토 및 승인을 받았으며, 후향적 연구이기 때문에 환자의 동의는 받 지 않았다(No. KC21RASI0171).

\section{평가 방법}

치료 전후 환자의 음질을 평가하기 위하여 GRBAS scale 을 통한 청지각적 검사를 '산책' 문단(정옥란, 1994) 낭독 음성 샘플을 사용하여 시행하였으며, 음성치료 및 음성검사 경력이 5 년 이상인 숙련된 언어재활사 2 명이 시행하였다. GRBAS scale은 G (grade), R (rough), B (breathy), A (asthenic), S (strained)의 항목으로 구성되어 있으며, 각각 4점 척도 $(0=$ normal, $1=$ mild, $2=$ moderate, $3=$ severe)로 평가되었다.

음향학적 검사 데이터는 Computerized Speech Lab (CSL; model 4150B, KayPENTAX Elemetrics, Lincoln Park, NJ, USA)의 Multiple-Dimensional Voice Program을 이용하 
여 모음 / / / 연장 발성 시 주파수변동률(jitter), 진폭변동률 (shimmer), 소음대배음비(noise to harmonic ratio, NHR)를 측정하였으며, CSL의 voice range profile을 이용하여 음도 범위(semitone range)가 수집되었다. 또한, electroglottographic을 이용하여 모음 / / 발성 시 폐쇄지수(closed quotient_vowel, CQ_V)를 측정하였다.

공기역학적 검사는 CSL의 real-time pitch를 이용하여 최 대연장발성시간을 측정하였다. 측정 시, 가능한 공기를 많이 들이마시고 / / /를 최대한 길게 발성하도록 유도하였으며, 3회 측정 후 가장 길게 발성한 시간으로 선택하였다.

후두 소견 검사는 비디오스트로보스코피를 사용하여 이비 인후과 전문의에 의해 시행되었으며, 치료 전후 성문틈 중증 도를 3점 척도로 정상군을 0 , 경도의 성문틈을 1 , 방추형 성 문틈(spindle-shaped gap)을 2로 평가하였다. MTD 중증도 평가는 Schönweiler 등[10]에 의해 제시된 4점 척도로 평가 되었는데, 정상군을 0 , 비디오스트로보스코피상 성문상부의 압축으로 인해 성대의 $1 / 3$ 이 가려진 경우 $1,1 / 2$ 이 가려진 경우 2 , 성대 전체가 가려진 경우 3 으로 평가하였다.

\section{치료 절차}

모든 대상자의 음성치료는 연구자가 재구성한 활창훈련과 허밍을 결합한 음성치료로 진행하였다. 치료 횟수는 $1-5$ 회, 평균 1.9 회로 나타났으며, 치료 횟수별 환자 분포는 1 회 11 명, 2회 6명, 3회 2명, 4회 3명, 5 회 1명이었다. 치료는 1-2주 간격 으로 한번, 1 회당 40 분 이내로 진행하였으며, 치료 후 5 분 이 내의 간단한 동영상을 녹화하여 환자 수준에 맞는 과제를 하 루 10분씩, 2-3회 수행하도록 권고하였다. 모든 치료는 5년 이 상의 음성치료 경력을 가진 한 명의 언어재활사가 진행하였다.

치료의 첫 절차는 환자에게 질환에 대해 설명하는 5 분 이 내의 간단한 설명이었다. 이후 바로 직접적인 음성치료를 시 작하는데, 허밍으로 한 옥타브(octave) 내에서 저음-고음-저 음을 거치는 활창훈련을 마치 '소 울음소리’를 흥내내듯이 산 출하여 반복하도록 지시하였다. 이때 전방화된 소리가 나도 록 유도하며, 구강이나 인두강이 좁혀진 듯한 억압된 소리가 날 경우 저작하기 접근법[11]을 통해 자연스러운 구강개방을 유도한 뒤 소리를 내도록 안내했다.

환자가 목표한 소리를 성공적으로 5번 이상 반복할 수 있 는 경우에 발음만 모음으로 바꾸어 같은 활창훈련 과제를 진 행하였다. Boone 등[11]은 혀가 뒤쪽에 위치할 때 소리의 초 점이 뒤쪽에서 산출된다고 하였는데, 본 연구에서는 소리의 전방화를 위해 전설 모음인 / / 로 시작하여 / / /, / / / 순서로 구강개방을 유도하였다.

\section{분석 방법}

통계 프로그램은 SPSS 21.0 (IBM Corp., Armonk, NY, USA)을 사용하였다. 성문틈을 가진 환자들에게 활창훈련과 허밍을 결합한 음성치료의 효과를 관찰하기 위하여 치료 전 후 음성검사 데이터를 대응표본 t-검정(paired t-test)을 사용 하여 분석하였다.

또한 성대구증 환자에서 음성치료의 효과를 살펴보기 위 하여 전체 대상자 중 성대구증 환자의 치료 전후 음성검사 데 이터를 대응표본 $\mathrm{t}$-검정을 사용하여 분석하였다. 모든 통계의 유의수준은 0.05 이하로 설정하였다.

\section{결 과}

성문틈 환자의 음성치료 효과

치료 전후 전체 대상자 23 명의 음성검사 결과(Table 1), 청 지각적 검사의 $\mathrm{G}, \mathrm{R}, \mathrm{B}, \mathrm{A}, \mathrm{S}$, 음향학적 검사의 jitter, shimmer, NHR, semitone range, 공기역학적 검사의 MPT에서 치료 후 통계학적으로 유의미한 음성 개선이 나타났다. 또한, 비디오스트로보스코피를 통한 후두 소견 검사에서 치료 후 성문틈과 $\mathrm{MTD}$ 의 중증도가 통계학적으로 유의미한 개선을 보였다 $(\mathrm{p}<0.05)$.

치료 전후 후두 소견을 분석해 보면, 치료 전 전체 23명의 환 자 중 14명(60.8\%)이 성문틈 개선을 보였고, 그중 10명(43.4\%) 은 성문틈이 사라진 후두 소견이 관찰되었다.

또한, 치료 전 MTD 소견이 관찰된 12명의 환자 중 4명(33.3\%) 이 MTD 중증도 개선과 함께 성문틈 중증도 개선을 보였고,

Table 1. Comparison of voice evaluation and videostroboscopy findings before and after therapy $(n=23)$

\begin{tabular}{lccc}
\multicolumn{1}{c}{ Parameter } & Pre therapy & Post therapy & $\mathrm{p}$ \\
$\mathrm{G}$ & 1.52 & 0.78 & $<0.001^{* *}$ \\
$\mathrm{R}$ & 0.74 & 0.43 & $0.016^{*}$ \\
$\mathrm{~B}$ & 1.35 & 0.61 & $<0.001^{* *}$ \\
$\mathrm{~A}$ & 0.22 & 0.00 & $0.022^{*}$ \\
$\mathrm{~S}$ & 0.35 & 0.13 & $0.022^{*}$ \\
Jitter & 2.58 & 0.97 & $<0.001^{* *}$ \\
Shimmer & 5.61 & 3.28 & $0.004^{* *}$ \\
NHR & 0.15 & 0.12 & $0.002^{* *}$ \\
Semitone range & 23.87 & 27.52 & $<0.001^{* *}$ \\
MPT & 12.55 & 14.88 & $0.013^{*}$ \\
CQ_V (SD) & $41.46(1.97)$ & $43.07(1.65)$ & 0.151 \\
Glottal gap & 1.26 & 0.57 & $<0.001^{* *}$ \\
MTD & 0.78 & 0.61 & $0.043^{*}$
\end{tabular}

Data are presented as mean. ${ }^{*} \mathrm{p}<0.05 ;{ }^{* *} \mathrm{p}<0.01$. G, grade; R, rough; $\mathrm{B}$, breathy; A, asthenic; $\mathrm{S}$, strained; NHR, noise to harmonic ratio; MPT, maximum phonation time; CQ_V, closed quotient_vowel; MTD, muscle tension dysphonia 
3 명(25\%)은 성문틈 중증도는 개선되었으나 MTD 중증도는 개선되지 않았으며, 5명(41.6\%)은 성문틈과 MTD 중증도 모 두 개선되지 않았다(Fig. 1).

\section{성대구증 환자의 음성치료 효과}

치료 전후 성대구증 환자 14 명의 음성 검사 데이터를 분석 한 결과(Table 2), G, R, B, jitter, shimmer, NHR, semitone range, MPT에서 치료 후 통계학적으로 유의미한 음성 개선 이 나타났으며, 후두 소견 검사에서 치료 후 성문틈 중증도가 유의미한 개선을 보였다 $(\mathrm{p}<0.05)$.

\section{고 찰}

본 연구에서 사용한 치료는 VFE에서 사용되는 활창훈련 과 반폐성도훈련 중 하나인 허밍을 결합한 치료법이다. VFE

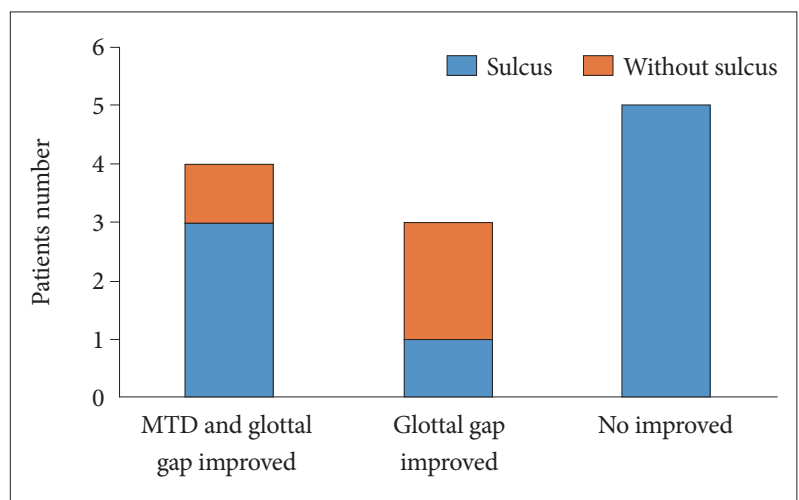

Fig. 1. Videostroboscopy findings after voice therapy of vocal cord gap patients with MTD $(n=12)$. MTD, muscle tension dysphonia.

Table 2. Comparison of voice evaluation and stroboscopy findings before and after therapy in sulcus vocalis group $(n=14)$

\begin{tabular}{lccc}
\multicolumn{1}{c}{ Parameter } & Pre therapy & Post therapy & $\mathrm{p}$ \\
$\mathrm{G}$ & 1.57 & 0.86 & $<0.001^{* *}$ \\
$\mathrm{R}$ & 0.86 & 0.57 & $0.040^{*}$ \\
$\mathrm{~B}$ & 1.43 & 0.64 & $<0.001^{* *}$ \\
$\mathrm{~A}$ & 0.07 & 0.00 & 0.336 \\
$\mathrm{~S}$ & 0.29 & 0.21 & 0.336 \\
Jitter & 2.55 & 1.03 & $0.004^{* *}$ \\
Shimmer & 6.17 & 3.60 & $0.032^{*}$ \\
NHR & 0.16 & 0.12 & $0.001^{* *}$ \\
Semitone range & 22.71 & 27.71 & $0.001^{* *}$ \\
MPT & 11.60 & 14.37 & $0.005^{* *}$ \\
CQ_V (SD) & $42.39(1.88)$ & $44.16(1.90)$ & 0.222 \\
Glottal gap & 1.21 & 0.71 & $0.003^{* *}$ \\
MTD & 1.00 & 0.79 & 0.082 \\
\hline Data arepresented
\end{tabular}

Data are presented as mean. ${ }^{*} \mathrm{p}<0.05 ;{ }^{* *} \mathrm{p}<0.01$. G, grade; R, rough; $\mathrm{B}$, breathy; A, asthenic; S: strained; NHR, noise to harmonic ratio; MPT, maximum phonation time; CQ_V, closed quotient_vowel; MTD, muscle tension dysphonia
와 반폐성도훈련은 선행연구에서 성문틈을 가진 환자들에게 사용되어 그 효과를 증명해왔다.

$\mathrm{VFE}$ 는 체계적인 호흡훈련과 성대훈련을 통해 호흡, 근육 의 협응력 등과 같은 음성생성에 관련된 하위 기능들을 재조 정하는 치료법이다[5,12]. 총 네 가지 단계 중 두 가지 단계에 서 활창훈련을 포함하고 있으며, 이 두 가지 단계는 저음-고음 활창과 고음-저음 활창으로 나누어진다.

본 연구자들은 성문틈이 성문 자체만의 문제가 아니라 호 흡, 근긴장 등을 포함하는 총체적인 발성 패턴 문제로 인해 발 생한다고 여겼기 때문에, 활창훈련을 이용하여 호흡 및 근육 협응력을 향상시키는 것에 초점을 두었다. 다만 VFE에서 사 용되는 활창훈련과 달리 본 연구에서는 고령의 환자가 여러 가지 과제로 인한 혼동을 겪지 않도록 '저음-고음-저음'을 거 치는 하나의 활창훈련을 반폐성도훈련인 허밍을 통해 시행하 도록 하였다.

반폐성도훈련은 선행연구들에서 성대접촉률 향상과 음질 개선에 대한 효과가 입증되어 왔으며[13], 그중 입술 떨기(liptrill)를 이용한 치료는 성문틈을 가진 환자에게 단기적으로 시행되어도 효과적이라고 보고되었다[7]. 그러나 입술 떨기를 수행하지 못하는 환자의 경우 과제 진행에 어려움을 겪을 수 있는데, 허밍은 입술 떨기에 비해 수행하기 용이하고 Laxvox 또는 빨대를 이용한 반폐성도훈련과 달리 특별한 도구가 필 요하지 않다는 장점이 있다. 특히 최근의 COVID-19와 같은 유행성 질환으로 비말주의 감염이 주의되는 상황에서 밀폐된 공간에서 시행되는 음성치료 시 다른 반폐성도훈련에 비해 에어로졸(aerosol)의 발생을 최소화할 수 있다는 장점을 가 지고 있다.

결과적으로 본 연구에서는 총체적인 발성 패턴에 변화를 줄 수 있는 활창훈련과 비교적 수행하기 쉬운 허밍을 이용하 여 음성치료 효과를 극대화시키고자 하였으며, 이 기법을 이 용한 음성치료가 성문틈을 가진 환자들의 음성 개선에 미치 는 효과를 보고자 하는 것을 본 논문의 목표로 삼았다.

음성치료 후 전체 성문틈 환자의 음성검사 및 후두 소견을 분석한 결과, 대부분의 음성검사 데이터와 후두 소견 중증도 에서 통계학적으로 유의미한 개선이 나타났다. 이를 통해 기존 의 선행연구들과 본 연구에서 나타난 결과가 일치함을 알 수 있다. de Hoop 등[14]은 허밍이 성문상부압축을 호전시키고 성대의 안정적인 접촉을 유도한다고 보고하였으며, Mau 등[15] 은 성문틈이 있는 노인성 음성장애 환자들을 대상으로 다양 한 음성치료 기법을 사용하여 음성 개선의 효과를 보고한 연 구에서 성문틈이 작은 환자에게는 $\mathrm{VFE}$ 를, 성문틈이 큰 환 자들에게 고음 산출 훈련을 적용하여 음성과 성문틈 간격이 호전되었다고 보고하였다. 
그러나 연구자들이 활창훈련과 허밍을 결합한 치료가 성문 틈 환자들의 성대접촉 향상에 도움을 주어 CQ_V의 수치가 치료 후 유의미하게 향상될 것이라고 예상한 것과 달리, 치료 후 CQ_V의 평균 값에 향상이 있었지만 통계적으로 유의미한 개선은 나타나지 않았다. Lee 등[16]이 보고한 것처럼 전통적 인 반폐성도훈련의 경우 모음발성에 비해 낮은 $\mathrm{CQ}$ 를 보이는 데, 본 연구의 결과는 반폐성도훈련으로 인한 발성역치 압력 의 저하와 음성치료로 인한 성대접촉의 증가가 상쇄된 결과 라고 추측된다. 허밍이 성대접촉에 미치는 영향을 알아본 de Hoop 등[14]의 연구에서도 허밍을 이용한 훈련 후 CQ 수치에 유의미한 차이가 나타나지 않았다고 보고하였다.

흥미로운 점은 후두 소견을 분석했을 때, $\mathrm{MTD}$ 를 동반한 환자 중 성문틈 개선을 보인 환자들은 MTD 중증도에 개선 이 있는 경우가 있었고, 성문틈 개선을 보이지 않은 환자들은 치료 후 모두 MTD 중증도에 개선이 없었는데, 이는 성문틈으 로 인한 2차성 MTD가 성문틈이 개선되며 함께 사라진 것으 로 보인다. 실제 임상 현장의 후두 소견에서 성문틈과 MTD가 동시에 관찰되는 경우 음성치료사들이 치료 목표를 정하기 혼 란스러운 경우가 있다. 본 연구의 결과는 이러한 환자의 경우 선행적인 성문틈 개선이 MTD도 함께 개선시킬 수 있다는 근 거가 될 것으로 보인다.

성대구증으로 인한 성문틈 환자의 음성치료 효과를 분석 한 결과, 음성 검사 데이터와 후두 소견에서 통계학적으로 유 의미한 개선을 보였다. Nam 등[7]은 성문틈 환자들을 대상으 로 입술 떨기를 이용하여 음성치료를 시행한 연구에서, 치료 후 성대구증 환자군의 음향학적 수치(jitter, shimmer, NHR) 에서 유의미한 개선이 나타나지 않았다고 보고하였다. 반면, 본 연구에서는 성대구증 환자군에서도 음향학적 수치의 유 의미한 개선이 나타났는데, 이는 고음도의 반폐성도훈련이 더 많은 성문폐쇄를 촉진시키기 때문에 $[15,17]$ 활창 시 고음도 산 출이 성대접촉 양상의 변화를 가져온 결과로 보인다. 이러한 결과는 비교적 음성치료의 효과가 적은 성대구증 환자군에서 활창훈련과 허밍을 결합한 치료법이 음성 개선에 효과적이라 는 것을 의미한다.

선행연구들에서 성대구증 환자들의 음성 개선에 대하여 음 성치료가 주된 수단으로 사용되지 않고, 음성악화 방지 및 수 술 후 보조적인 수단으로 사용한다고 보고되기도 하였다[11,18]. 이러한 기존의 연구들과 본 연구의 차이점을 검토해본 결과, 음성 전방화의 유무가 치료 결과에 영향을 미치는 것으로 분 석된다. 성대구증 환자의 음성치료에 대하여 회의적으로 보고 하거나 보조적 수단으로 보고한 연구들에서는 음성 전방화에 대한 언급이 없었으며[7,18], 비교적 좋은 효과를 보고한 연구 에서는 음성 전방화 또는 음성배치에 대한 언급이 있었다[8,9].
실제로 본 연구자는 치료 시 ‘음성을 산출하는 행위’보다는 ‘어 떤 음성을 산출하는가'에 초점을 맞추어 치료를 진행하였으 며, 치료 절차에서 언급했듯이 '소 울음소리' 같은 소리를 내도 록 하여 구강 및 인두강이 최대한 확장된 소리를 유도하는 것 에 집중했다. 또한 본 연구자의 치료과정에서 관찰된 임상 경 험상 음성 전방화의 수행력이 높은 환자들이 치료 초기 음질 개선과 음성치료의 예후가 좋았다. 3 회 이상의 치료를 받은 일부의 환자들은 1-2회기의 치료에서 음성 전방화를 수행하 지 못한 환자들이었다. 이처럼 활창과 허밍을 결합한 음성치 료는 후두 긴장 완화는 물론 음성 전방화를 동시에 실행하는 데 목적을 두었다. 따라서 성대구증 환자들이 보이는 잘못된 발성 패턴을 수정할 수 있었기에 기존 연구의 한계를 극복한 것으로 여겨진다. 그러나 아쉽게도 이러한 부분은 현재 이비 인후과에서 사용하는 검사 도구로는 포먼트 분석을 통한 부 분적인 측정만 가능할 뿐, 정확한 측정은 불가능하다는 한계 가 있다.

추가적으로 본 연구에서는 성문틈의 중증도를 0-2의 3점 척도로 분류하였는데, 14 명의 성대구증 환자들 중 11 명이 치 료 전 1점으로 분류되어 비교적 경증의 성문틈을 가진 환자 들이 높은 비율을 나타냈다. 이처럼 중증 성문틈 환자의 적 은 비율이 본 연구에서 나타난 결과에 영향을 미쳤을 것으로 보인다.

한편, 성대구증 환자군의 치료 후 $\mathrm{A}, \mathrm{S}, \mathrm{MTD}$ 중증도에서 전반적인 개선은 있었지만 통계적으로 유의미한 결과가 나타 나지 않았다. 이는 성대구증과 같은 기질적 성문틈의 경우 반 폐성도 기법의 효과가 제한되기 때문인 것으로 보이며[7], A 의 경우 치료 전 평가에서 약한 음성을 나타낸 환자가 적어 개선의 여지가 없었던 것이 원인인 것으로 보인다.

\section{결 론}

결론적으로 활창훈련과 허밍을 결합한 음성치료는 성문틈 을 가진 환자에게 효과적인 것으로 보이며, 성대구증으로 인 한 성문틈 환자에게도 이 치료법이 효과적인 것으로 보인다. 아울러 성문틈과 MTD가 동시에 관찰되는 경우, 성문틈 개 선을 위한 치료가 $\mathrm{MTD}$ 를 함께 개선시킬 수 있다는 것을 고 려해야 한다.

다만 본 연구는 치료하지 않은 대조군이 없고, 성대구증 환 자군의 경우 대상자 수가 충분하지 않았으며, 치료 후 음성 개선 효과를 장기적으로 관찰하지 않았다는 제한점이 있다. 향후 연구에서는 대조군과 함께 추가적인 대상자를 확보하고 지속적인 추적 관찰을 통하여 음성치료의 장기적인 효과를 확인해야 할 것으로 생각된다. 
중심 단어: 성문틈; 성대구증; 음성치료; 활창; 허밍.

Acknowledgments

None.

Conflicts of Interest

The authors have no financial conflicts of interest.

Authors' Contribution

Conceptualization: Dong Il-Sun, Dae-Yong Jung. Data curation: Dae-Yong Jung, Yeon-Shin Hwang, Mi-Ran Shim, Geun-Jeon Kim. Formal analysis: Dae-Yong Jung. Investigation: Dae-Yong Jung, Mi-Ran Shim, Geun-Jeon Kim. Methodology: Dae-Yong Jung, Yeon-Shin Hwang. Project administration: Dong-Il Sun. Supervision: Dong-Il Sun. Approval of final manuscript: all authors.

\section{REFERENCES}

1. Ferrand CT. Voice disorders: Scope of theory and practice. 1st ed. Boston: Pearson Education Inc;2012.

2. Omori K, Slavit DH, Kacker A, Blaugrund SM. Influence of size and etiology of glottal gap in glottic incompetence dysphonia. Laryngoscope 1998;108(4 Pt 1):514-8.

3. Jung DY, Wi JY, Kim ST. Efficacy of laughing voice treatment (SKMVTT $^{\mathbb{B}}$ ) in benign vocal fold lesions. Phonetics Speech Sci 2018;10(4): $155-61$.

4. Kaneko M. Voice therapy for the elderly. In: Makiyama K, Hirano S, editors. Aging Voice. Singapore: Springer Nature;2017. p.83-94.

5. Kaneko M, Hirano S, Tateya I, Kishimoto Y, Hiwatashi N, Fujiu-Kurachi $\mathrm{M}$, et al. Multidimensional analysis on the effect of vocal function exercises on aged vocal fold atrophy. J Voice 2015;29(5):638-44.

6. Portone C, Johns MM 3rd, Hapner ER. A review of patient adherence to the recommendation for voice therapy. J Voice 2008;22(2):192-6.

7. Nam IC, Kim SY, Joo YH, Park YH, Shim MR, Hwang YS, et al. Effects of voice therapy using the lip trill technique in patients with glottal gap. J Voice 2019;33(6):949.e11-9.

8. Kumar R, Sharma P, Vir D, Panda NK. Voice therapy outcomes in type-I sulcus vocalis: Case studies. Int J Clin Exp Otolaryngol 2016;2(5):4850.

9. Rajasudhakar R. Effect of voice therapy in sulcus vocalis: A single case study. S Afr J Commun Disord 2016;63(1):e1-5.

10. Schönweiler R, Wohlfarth K, Dengler R, Ptok M. Supraglottal injection of botulinum toxin type A in adductor type spasmodic dysphonia with both intrinsic and extrinsic hyperfunction. Laryngoscope 1998;108(1 Pt 1):55-63.

11. Boone DR, McFarlane SC, Von Berg SL, Zraick RI. The voice and voice therapy. 9th ed. Boston: Pearson Education Inc;2013.

12. Stemple JC, Lee L, D'Amico B, Pickup B. Efficacy of vocal function exercises as a method of improving voice production. J Voice 1994; 8(3):271-8.

13. de Oliveira KGSC, de Lira ZS, da Silva HJ, Lucena JA, Gomes AOC. Oropharyngeal geometry and the singing voice: Immediate effect of two semi-occluded vocal tract exercises. J Voice 2020 Jul 23 [Epub]. Available from: https://doi.org/10.1016/j.jvoice.2020.06.027.

14. de Hoop T, Ogawa M, Iwahashi T, Umatani M, Hosokawa K, Kato C, et al. Humming facilitates a gradual increase in vocal intensity by alleviating the enhancement of vocal fold contact and supraglottic constriction. J Voice 2021;35(1):156.e1-13.

15. Mau T, Jacobson BH, Garrett CG. Factors associated with voice therapy outcomes in the treatment of presbyphonia. Laryngoscope 2010; 120(6):1181-7.

16. Lee SJ, Lee KY, Lim JY, Choi HS. A comparison of acoustic \& electroglottographic measures according to voiced lip trill methods. Phonetics Speech Sci 2017;9(4):107-14.

17. Cordeiro GF, Montagnoli AN, Nemr NK, Menezes MH, Tsuji DH. Comparative analysis of the closed quotient for lip and tongue trills in relation to the sustained vowel /E/. J Voice 2012;26(1):17-22.

18. Giovanni A, Chanteret C, Lagier A. Sulcus vocalis: A review. Eur Arch Otorhinolaryngol 2007;264(4):337-44. 